\title{
Cisalhamento na Linha de Cola de Eucalyptus sp. Colado com Diferentes Adesivos e Diferentes Gramaturas
}

\author{
Juliana Jerásio Bianche ${ }^{1}$, Ana Paula Mendes Teixeira ${ }^{1}$, João Paulo Silva Ladeira ${ }^{1}$, \\ Angélica de Cássia Oliveira Carneiro ${ }^{1}$, Renato Vinícius Oliveira Castro ${ }^{2}$, \\ Ricardo Marius Della Lucia ${ }^{1}$ \\ ${ }^{1}$ Universidade Federal de Viçosa - UFV, Viçosa/MG, Brasil \\ ${ }^{2}$ Universidade Federal de São João Del Rei - UFSJ, Sete Lagoas/MG, Brasil
}

\begin{abstract}
RESUMO
O objetivo deste trabalho foi avaliar a resistência ao cisalhamento na linha de cola de juntas de Eucalyptus sp. coladas com diferentes adesivos e diferentes gramaturas. Para a colagem das juntas foi utilizada a madeira de Eucalyptus sp., dois adesivos de cura a quente (fenol-formaldeído e melamina-formaldeído), quatro adesivos de cura a frio [resorcinol-formaldeído, silicato de sódio, PVA (acetato de polivinila) e poliuretano à base de mamona], empregando-se gramaturas de $150 \mathrm{~g}, 200 \mathrm{~g} \mathrm{e} 250 \mathrm{~g} / \mathrm{m}^{2}$ em face dupla. Foram determinados aresistência ao cisalhamento e à falha na madeira, e cisalhamento em condição úmida. Os resultados obtidos indicaram que os adesivos de mamona e resorcinol apresentaram maior resistência ao cisalhamento na linha de cola na condição seca. Os adesivos de mamona e fenol-formaldeído apresentaram maior percentual de falha na madeira na condição seca.
\end{abstract}

Palavras-chave: adesivo de mamona, silicato de sódio, colagem.

\section{Shear in the Glue Line of Eucalyptus sp. Bonded with Different Adhesives and Weights}

\begin{abstract}
This work aimed to evaluate the shear strength of glue line joints of Eucalyptus sp bonded with different adhesives and weights. Bonding of Eucalyptus sp was performed using two hot-curing adhesives (phenol-formaldehyde and melamine-formaldehyde), four cold-curing adhesives (resorcinol-formaldehyde, sodium silicate, PVA (polyvinyl acetate) and castor oil-based polyurethane, the weights were 150,200 and $250 \mathrm{~g} / \mathrm{m}^{2}$ double sided.Shear strength and failure in wood and shear in wet conditions were determined. According to the results, castor and resorcinol adhesives showed higher shear strength in the glue line in dry condition. Castor and phenol formaldehyde adhesives showed higher failure percentage in wood in dry condition.
\end{abstract}

Keywords: castor adhesive, sodium silicate, bonding.

\section{INTRODUÇÃO}

O processo de colagem da madeira ocorre através da adesão, que é um fenômeno físico-químico, o qual prevê um mecanismo de interação entre superfícies sólidas, a aderente e a adesiva, que é uma substância com capacidade de manter unidos outros materiais em sua superfície. A função de um adesivo, além de 
aderir dois substratos, é fluir e preencher espaços vazios entre as juntas a serem coladas, diminuindo assim a distância entre elas, gerando interações entre $\mathrm{o}$ adesivo e o substrato.

Os mecanismos de adesão podem ser explicados pela adesão química, mecânica e de difusão de polímeros. A adesão química ocorre quando há formação de ligações primárias e iônicas ou covalentes e/ou forças intermoleculares secundárias. Na teoria mecânica, o adesivo, devido a sua fluidez, penetra em substratos porosos, como a madeira, ocorrendo posteriormente a solidificação, com a formação de "ganchos" presos entre os substratos. E, de acordo com a teoria da difusão de polímeros, a adesão ocorre através da difusão de segmentos de cadeias de polímeros a nível molecular (Almeida, 2009).

A densidade da madeira apresenta uma relação inversa com a porosidade e a ação de penetração de adesivos na estrutura lenhosa. Em madeiras de baixa densidade, ocorre maior penetração do adesivo, podendo acarretar uma linha de cola "faminta", ou seja, quantidade insuficiente de adesivo na linha de cola. Por outro lado madeiras de alta densidade apresentam baixa permeabilidade ao adesivo o que, consequentemente, poderá resultar numa linha de cola espessa, superficial e menos resistente (Iwakiri, 2005).

Para avaliar o desempenho de um adesivo, geralmente ele é tensionado como, por exemplo, em cisalhamento na linha de cola, a determinada temperatura e condições de umidade durante um tempo específico (Forest Products Laboratory, 1999).

$\mathrm{O}$ adesivo é um componente importante, com implicações técnicas e econômicas na utilização dos produtos à base de madeira. $\mathrm{O}$ seu custo pode chegar até $50 \%$ do preço total do produto final (Carneiro et al., 2004). Os adesivos são classificados de acordo com sua composição química, podendo ser orgânicos ou inorgânicos. Os adesivos inorgânicos são geralmente à base de silicatos, muito utilizados nas formulações para a produção de cimentos, colagem de substratos porosos e chapas metálicas (Fiorelli, 2002). Entretanto, estudos desse adesivo para a colagem de madeira ainda é incipiente, fazendo-se necessário o conhecimento das propriedades do silicato de sódio.

O grupo sintético é o mais importante e o mais empregado pela indústria madeireira, por apresentar grande resistência à ação da água e por esses produtos não sofrerem a ação de microorganismos. Esses adesivos podem ser classificados em termofixos e termoplásticos (Fiorelli, 2002).

Adesivos termofixos são aqueles que endurecem por meio de reações químicas ativadas por temperatura ou catalisadores. Dentre eles destacam-se: fenol-formaldeído, uréia-formaldeído, resorcinol-formaldeído, melamina-formaldeído e poliuretanos.

A busca por materiais oriundos de fontes renováveis fez com que fossem desenvolvidos outros adesivos, como o adesivo poliuretano à base de mamona. O avanço observado em sua tecnologia de produção está relacionado à vantagem de não emanar formaldeído, além de proporcionar um produto com alta resistência à umidade, de manipulação à temperatura ambiente $\mathrm{e}$ grande resistência mecânica (Dias et al., 2006).

O objetivo deste trabalho foi avaliar a resistência ao cisalhamento na linha de cola de juntas de Eucalyptus sp. coladas com diferentes adesivos e diferentes gramaturas.

\section{MATERIAL E MÉTODOS}

O trabalho foi realizado no laboratório de Painéis e Energia da Madeira da Universidade Federal de Viçosa, localizado no município de Viçosa, Minas Gerais. Foi utilizada a madeira de Eucalyptus sp. proveniente da região de Viçosa, MG, obtida em forma de tábuas, que foram transformadas em lâminas de $40 \mathrm{~cm}$ de comprimento, $10 \mathrm{~cm}$ de largura e $0,6 \mathrm{~cm}$ de espessura. Determinou-se a densidade básica da madeira utilizando-se o método de imersão em água, segundo Vital (1984).

Foram utilizados fenol-formaldeído e melamina-formaldeído, de cura a quente, e resorcinol-formaldeído, silicato de sódio, PVA (acetato de polivinila) e poliuretano à base de mamona, de cura a frio

Os adesivos fenol-formaldeído, melamina-formaldeído e resorcinol-formaldeído foram fornecidos pela indústria Momentive Química do Brasil Ltda e o adesivo de silicato de sódio fornecido pela Tubominas Indústria e Comércio Ltda. O adesivo de Cascorez (PVA) foi adquirido no comércio local e o adesivo poliuretano à base de mamona foi fornecido pela KEHL Indústria e Comércio Ltda. 


\subsection{Propriedades dos adesivos}

Foram determinados viscosidade, teor de sólidos, $\mathrm{pH}$, tempo de gelatinização (gel time) e tempo de trabalho dos adesivos. O tempo de trabalho foi determinado apenas para os adesivos bicomponentes (resorcinol-formaldeído e à base de mamona) e o tempo de gelatinização determinado somente para os adesivos de cura a quente.

Utilizou-se para o adesivo de resorcinol-formaldeído uma proporção de 5:1 de resorcinol/endurecedor e, para o adesivo à base de mamona, foi utilizada relação de poliol/endurecedor igual a 1,5:1. Ao adesivo de melamina-formaldeído foi adicionado $1,5 \%$ de sulfato de amônio (catalisador) sobre o teor de sólidos.

\subsection{Colagem e avaliação das juntas}

A escolha das lâminas de madeira foi feita considerando-se a sua massa, isenção de defeitos e limpeza. Teve-se o cuidado de separar lâminas com mesma densidade para a formação das juntas de madeira. A prensagem das juntas de madeira coladas com adesivos de cura a frio foi realizada em prensa manual, utilizando-se um torquímetro com pressão de $12 \mathrm{kgf} / \mathrm{cm}^{2}$ para o fechamento dos parafusos. A prensa dispunha de três pares de barras rosqueadas em aço para aplicar a pressão de colagem. Foram aplicadas em face dupla três gramaturas de $150 \mathrm{~g}, 200 \mathrm{~g}$ e $250 \mathrm{~g} / \mathrm{m}^{2}$. O espalhamento do adesivo foi feito nas duas faces das lâminas, com auxílio de um pincel. Considerou-se tempo de montagem em aberto apenas para os adesivos de resorcinol-formaldeído e acetato de polivinila, sendo igual a 5 minutos. $\mathrm{O}$ tempo em fechado foi igual a 15 minutos. Depois as juntas coladas foram levadas à prensa manual por um período de 24 horas.

A colagem com adesivos de cura a quente foi feita em prensa de laboratório marca INCO, empregando-se pressão de $12 \mathrm{kgf} / \mathrm{cm}^{2}$ e tempo de prensagem de 8 minutos, a temperatura de $150^{\circ} \mathrm{C}$. Foram produzidas 54 juntas coladas, sendo 6 adesivos e 3 gramaturas, com 3 repetições para cada tratamento. Para a determinação da resistência da linha de cola ao cisalhamento e a porcentagem de falha na madeira, as amostras foram seccionadas de acordo com a norma ASTM D-2339/93 (ASTM, 1993). Foram obtidos 12 corpos de prova para cada repetição por tratamento, correspondendo a 36 corpos de prova por tratamento, com um total de 648 corpos de prova, que foram acondicionados a temperatura de $23^{\circ} \mathrm{C} \pm 1{ }^{\circ} \mathrm{C}$ e umidade relativa de $50 \pm 2 \%$. Após o equilíbrio higroscópico, a resistência ao cisalhamento e a falha na madeira foram determinadas. Foram ensaiados 12 corpos de prova, sendo 9 na condição seca e 3 na condição úmida. Cada corpo de prova teve sua área de cisalhamento medida com auxílio de um paquímetro. Para a condição úmida, a medição ocorreu antes da imersão dos corpos de prova em água a $20{ }^{\circ} \mathrm{C} \pm 3{ }^{\circ} \mathrm{C}$ por 24 horas. A determinação da qualidade das juntas coladas, através do ensaio de cisalhamento em condição úmida, foi feita de acordo com a norma ABNT NBR ISSO 12466-1: 2006 (ABNT, 2006) e os percentuais de falha na madeira foram mensurados com o auxílio de lâminas transparentes quadriculadas, com área delimitada em porcentagem.

\subsection{Análise estatística dos dados}

Foi adotado o delineamento inteiramente casualizado (DIC) com 18 tratamentos, sendo 6 adesivos, 3 gramaturas e 3 repetições, totalizando 54 unidades experimentais. Inicialmente, os dados foram submetidos aos testes de Lilliefors e Cochran, para testar a normalidade e homogeneidade das variâncias, respectivamente. Depois, os dados foram submetidos a análise de variância (ANOVA) e, quando estabelecidas diferenças significativas, os tratamentos foram comparados entre si, pelo teste Tukey, a 95\% de probabilidade. Foi analisado o efeito de dois fatores (tipo de adesivo e gramatura) e a interação entre eles na resistência da linha adesiva e na percentagem de falha na madeira.

\section{RESULTADOS E DISCUSSÃO}

A densidade básica média da madeira de Eucalyptus sp foi igual a $0,67 \mathrm{~g} / \mathrm{cm}^{3}$. Plaster et al. (2008) estudaram o comportamento de juntas coladas da madeira serrada de Eucalyptus sp e encontraram valores variando de $0,70 \mathrm{~g}$ a $0,99 \mathrm{~g} / \mathrm{cm}^{3}$, superiores ao encontrado neste trabalho. Os mesmos autores verificaram maior dificuldade de adesão em madeiras mais densas.

\subsection{Propriedades dos adesivos}

$\mathrm{Na}$ Tabela 1 são apresentadas as propriedades dos adesivos.

Verificou-se que os adesivos de silicato de sódio e melamina-formaldeído apresentaram menor valor médio de viscosidade (Tabela 1). Adesivos com 
baixa viscosidade resultam em melhor espalhamento sobre a superfície da madeira, devido à alta fluidez, o que contribui para maior penetração do adesivo e sua absorção pela madeira e, em situação extrema, pode resultar em linha de cola "faminta", ou seja, com quantidade insuficiente de adesivo na linha de cola. Mendoza (2010), avaliando o efeito da inclusão laminar nas propriedades de painéis aglomerados, encontrou para o adesivo de silicato de sódio viscosidade correspondente a $750 \mathrm{cp}$. Neste trabalho a viscosidade encontrada para o adesivo de silicato foi inferior à encontrada pela autora.

$\mathrm{O}$ adesivo de PVA apresentou a maior viscosidade média, o que lhe conferiu maior dificuldade de espalhamento, devido à baixa fluidez, o que pode ter favorecido a formação de uma linha de cola mais espessa, ocasionando ligação insuficiente no sistema madeira-adesivo e qualidade inferior da colagem. Lima et al. (2008), estudando a madeira de clones de Eucalyptus com três adesivos comerciais, verificaram que a viscosidade do adesivo de PVA fornecida pelo fabricante variou entre $10.000 \mathrm{cp}$ e $16.000 \mathrm{cp}$. A viscosidade encontrada neste trabalho para o adesivo de PVA foi inferior à obtida pelos autores.

Zangiácomo (2003), estudando espécies tropicais alternativas na produção de elementos de madeira laminada colada, constatou que o adesivo de resorcinol apresentou melhores resultados por ser menos viscoso que $\mathrm{o}$ adesivo a base de mamona. Esse fato foi verificado também neste trabalho, no qual a viscosidade do adesivo de mamona foi maior em relação à do resorcinol (Tabela 1). Lima et al. (2008) encontraram para o adesivo resorcinol-formaldeído viscosidade igual a $2.127 \mathrm{cp}$.

Para o teor de sólidos, os valores médios encontrados para os adesivos resorcinol e PVA foram iguais a $65 \%$ e $57,06 \%$, respectivamente (Tabela 1 ).
Marcati \& Della Lucia (1996), estudando o comportamento do angico-vermelho na adesão com PVA e resorcinol, encontraram teor de sólidos para resorcinol e PVA iguais a $52,06 \%$ e $48,56 \%$, respectivamente.

Observa-se na Tabela 1 que o adesivo à base de mamona apresentou o maior teor de sólidos em relação aos demais. O teor de sólidos é uma propriedade de grande importância na colagem e pode ser entendido como a quantidade de sólidos do adesivo que forma a linha de cola. $\mathrm{O}$ alto teor de sólidos pode contribuir para maior resistência na linha de cola.

Em se tratando de colagem de madeiras, é importante considerar a influência do $\mathrm{pH}$, tanto da madeira como do adesivo. $\mathrm{O} \mathrm{pH}$ da madeira varia conforme a espécie e situa-se na faixa de 3 a $6 . \mathrm{O}$ pH do adesivo não deve ultrapassar a faixa de 2,5 a 11, pois isso pode resultar em degradação das fibras de madeira. Verifica-se que os adesivos fenol-formaldeído e PVA apresentaram o maior e menor valor médio de $\mathrm{pH}$, respectivamente. Não foi determinado o $\mathrm{pH}$ para o adesivo de mamona devido a sua rápida polimerização e à dificuldade para retirar o adesivo do $\mathrm{pH}$ metro.

O tempo de trabalho se refere ao tempo de vida útil do adesivo, após sua preparação, até a fase de gel, quando atinge a máxima elasticidade, assim como o tempo de gelatinização. De modo geral, o tempo de trabalho dos adesivos não deve ser longo, pois isso demandaria um maior tempo de prensagem. Em contrapartida, tempo de trabalho curto acarreta problema de aplicação e de polimerização rápida do adesivo, provocando queda na resistência da linha de cola (Carneiro, 2006). Verifica-se que o adesivo à base de mamona apresentou tempo de trabalho igual a 38 minutos (Tabela 1). Jesus (2000), utilizando o adesivo a base de óleo de mamona na proporção em massa 1:1, observou que, em função do aumento da

Tabela 1. Valores médios para as propriedades dos adesivos.

Table 1. Mean values for the properties of adhesives.

\begin{tabular}{lccccccc}
\multirow{2}{*}{ Propriedades dos adesivos } & \multicolumn{7}{c}{ Adesivos } \\
\cline { 2 - 8 } & PVA & Silicato & Resorcinol & Mamona & Melamina & Fenol \\
Viscosidade (cp) & 9000 & 250 & 1543 & 3150 & 106,67 & 700 \\
Teor de sólidos (\%) & 57 & 49 & 65 & 90 & 45 & 48 \\
Tempo de gelatinização (s) & ND & ND & ND & ND & 98 & 128 \\
pH & 4,00 & 12 & 8 & ND & 8,88 & 12,49 \\
Tempo de trabalho (minutos) & ND & ND & 173 & 38 & ND & ND \\
\hline
\end{tabular}

ND: não determinado. 
viscosidade, o tempo de trabalho da mistura foi de 20 minutos. Para o adesivo de resorcinol foi encontrado tempo de trabalho igual a 173 minutos, sendo esse superior ao do adesivo de mamona.

\subsection{Resistência ao cisalhamento das juntas coladas}

Na Tabela 2 estão apresentados os valores médios por adesivo, observando-se, contudo, que apenas a resistência da linha de cola do silicato foi significativamente menor que as demais, exceto para a linha de cola com melamina-formaldeído.

Verifica-se que na condição seca houve efeito significativo na resistência ao cisalhamento. Não houve efeito significativo da gramatura e nem da interação entre adesivo e gramatura (Tabela 2).

Teles et al. (2010) estudaram o efeito da gramatura sobre a qualidade de juntas coladas e observaram que a eficiência e a qualidade da adesão do adesivo resorcinol-formaldeído foram influenciadas pela gramatura, mostrando aumento da resistência da junta colada com o aumento da gramatura do adesivo, sendo a maior resistência obtida na gramatura de $300 \mathrm{~g} / \mathrm{m}^{2}$.

$\mathrm{O}$ adesivo à base de mamona foi mais resistente, no entanto não diferiu significativamente dos adesivos resorcinol, PVA, melamina e fenol-formaldeído, diferindo apenas do adesivo a base de silicato de sódio, o qual apresentou os menores valores de resistência. $\mathrm{O}$ adesivo de silicato apresenta ligações fracas entre a sílica e o carbonato de sódio, resultando também em menor adesão à madeira. A baixa viscosidade do silicato pode ter ocasionado uma superpenetração do adesivo nas cavidades da madeira, gerando uma linha de cola "fina" e até mesmo faminta, podendo essa não ter sido suficiente para promover a adesão na linha de cola.

Os adesivos de mamona, resorcinol-formaldeído e PVA apresentaram maior valor médio de resistência para o cisalhamento na linha de cola da madeira na condição seca, entretanto não diferiram entre si. Esse fato pode ser atribuído à composição química desses adesivos. O adesivo de resorcinol deriva de reações de condensação entre o resorcinol e o formaldeído, produzindo não só ligações de elevada resistência mecânica mas também resistentes à água e às variações climáticas (Pizzi, 1994). Já a resistência do adesivo de mamona na linha de cola é atribuída aos monômeros uretanos produzidos pela reação de compostos hidroxilados com isocianatos. Além dos grupos uretanos, os poliuretanos podem ter hidrocarbonetos alifáticos e aromáticos, grupos éster e éter, uréia, amida, entre outros (Azevedo, 2009). Em relação ao PVA, durante a sua polimerização ocorre a eliminação da água de sua composição, sendo que a sua estrutura química se une, formando uma linha de cola homogênea e contínua, proporcionando resistência de colagem e elasticidade à junta adesiva.

Com relação à gramatura utilizada, observou-se para as juntas coladas com os adesivos de mamona e fenol-formaldeído que o aumento da gramatura ocasionou em aumento da resistência ao cisalhamento na linha de cola. O adesivo de fenol-formaldeído apresenta reações químicas de diversos fenóis com o formaldeído, produzindo uma resina termoestável, o que contribui para a resistência na linha de cola (Iwakiri, 2005).

Tabela 2. Valores médios de resistência ao cisalhamento em $\mathrm{kgf} / \mathrm{cm}^{2}$ na condição seca, em função da gramatura e tipo de adesivo.

Table 2. Average values of shear streng thin $\mathrm{kgf} / \mathrm{cm}^{2}$, in dry condition, depending on the weight and type of adhesive.

\begin{tabular}{lcccc}
\multirow{2}{*}{ ADESIVO } & \multicolumn{4}{c}{ GRAMATURA $\left(\mathbf{g} / \mathbf{m}^{2}\right)$} \\
\cline { 2 - 5 } & $\mathbf{1 5 0}$ & $\mathbf{2 0 0}$ & $\mathbf{2 5 0}$ & Média \\
FENOL & 42,23 & 54,80 & 88,65 & $61,89 \mathrm{a}$ \\
SILICATO & 43,50 & 31,96 & 42,51 & $39,32 \mathrm{~b}$ \\
\hline PVA & 64,03 & 57,09 & 72,30 & $64,47 \mathrm{a}$ \\
MELAMINA & 59,04 & 66,58 & 51,79 & $59,14 \mathrm{ab}$ \\
MAMONA & 76,64 & 77,64 & 82,64 & $78,97 \mathrm{a}$ \\
RESORCINOL & 78,17 & 70,21 & 68,65 & $72,34 \mathrm{a}$ \\
\hline Média & $60,60 \mathrm{~A}$ & $59,71 \mathrm{~A}$ & $67,76 \mathrm{~A}$ & \\
\hline
\end{tabular}

Mesmas letras maiúsculas entre gramaturas e minúsculas entre adesivos não diferem entre si pelo teste Tukey a 5\% de significância. 
Na Tabela 3 são apresentados os valores de resistência ao cisalhamento na linha de cola na condição úmida das juntas coladas, em função do tipo de adesivo e gramatura.

Observou-se para os adesivos de fenol-formaldeído e melamina-formaldeído um aumento da resistência ao cisalhamento, com aumento da gramatura que, contudo, foi significativo apenas para aqueles colados com fenol-formaldeído.

Verificou-se para as juntas coladas com o adesivo fenol-formaldeído que não houve diferença significativa entre as gramaturas $150 \mathrm{~g}$ e $200 \mathrm{~g} / \mathrm{m}^{2}$, sendo essas diferentes da gramatura de $250 \mathrm{~g} / \mathrm{m}^{2}$, a qual contribuiu para maior resistência das juntas coladas (Tabela 3). De modo geral, a elevada gramatura do adesivo favorece a fluidez, transferência, penetração e umedecimento da estrutura submicroscópica da madeira. No entanto, após a solidificação, pode originar linha de cola muito espessa e/ou a ultrapassagem, pelo excesso de adesivo, das bordas da madeira, durante a prensagem, tal situação dependerá da viscosidade do adesivo, pressão exercida sobre a madeira e características anatômicas da madeira.

Observa-se que os adesivos de silicato de sódio e PVA apresentaram os menores valores médios de resistência ao cisalhamento, ressaltando-se que alguns corpos de prova colados com o adesivo de silicato de sódio delaminaram-se quando imersos em água por 24 horas. Isso se deve a alta solubilidade do silicato em água. Devido a sua baixa resistência à umidade, os adesivos de silicato de sódio e PVA não devem ser utilizados em ambientes com alta umidade relativa ou em contato direto com a água.

Verifica-se que o adesivo de resorcinol-formaldeído apresentou o maior valor médio de resistência na condição úmida quando se utilizou a gramatura $200 \mathrm{~g} / \mathrm{m}^{2}$, e que não diferiu significativamente dos demais adesivos, exceto o silicato de sódio. Jesus (2000) relatou que o adesivo de resorcinol-formaldeído suporta qualquer condição a que venha a ser exposto, mesmo sob alterações climáticas, e que esse tipo de adesivo veio atender as necessidades do mercado por ser um adesivo impermeável e de cura a temperatura ambiente, com resistência estrutural elevada, superando a da própria madeira.

Vale ressaltar que o adesivo fenólico também apresenta como característica principal alta resistência à umidade, sendo classificado como de uso exterior (Iwakiri, 2005). Observou-se neste trabalho, contudo, que não houve diferença significativa entre o adesivo fenólico e o resorcinólico, provavelmente devido às ligações cruzadas formadas na polimerização desses adesivos, que aumentam a resistência na linha de cola (Pizzi \& Mittal, 1994).

\subsection{Falha na madeira}

Na Tabela 4 são apresentados os valores percentuais para a falha na madeira, condição seca, em função do tipo de adesivo e gramatura.

Observou-se que houve efeito significativo somente para o tipo de adesivo. A gramatura e interação adesivo-gramatura não tiveram efeito sobre a porcentagem de falha na madeira.

Tabela 3. Valores médios de resistência ao cisalhamento em $\mathrm{kgf} / \mathrm{cm}^{2}$ na linha de cola, condição úmida, em função da gramatura e tipo de adesivo.

Table 3. Average values of shear streng thin $\mathrm{kgf} / \mathrm{cm}^{2}$, glue line, moist condition, depending on the weight and type of adhesive.

\begin{tabular}{lcccc}
\multirow{2}{*}{ ADESIVO } & \multicolumn{4}{c}{ GRAMATURA $\left(\mathbf{g} / \mathbf{m}^{2}\right)$} \\
\cline { 2 - 5 } & $\mathbf{1 5 0}$ & $\mathbf{2 0 0}$ & $\mathbf{2 5 0}$ & Média \\
FENOL & $44,32 \mathrm{Ba}$ & $61,93 \mathrm{Ba}$ & $105,11 \mathrm{Aa}$ & 70,46 \\
SILICATO & $0,00 \mathrm{Ab}$ & $0,00 \mathrm{Ab}$ & $0,00 \mathrm{Ac}$ & 0,00 \\
PVA & $29,64 \mathrm{Aab}$ & $13,17 \mathrm{Ab}$ & $26,85 \mathrm{Abc}$ & 23,22 \\
MELAMINA & $44,93 \mathrm{Aa}$ & $53,77 \mathrm{Aa}$ & $59,84 \mathrm{Ab}$ & 52,85 \\
MAMONA & $47,64 \mathrm{Aa}$ & $57,50 \mathrm{Aa}$ & $55,12 \mathrm{Ab}$ & 53,42 \\
RESORCINOL & $65,52 \mathrm{Aa}$ & $84,36 \mathrm{Aa}$ & $54,70 \mathrm{Ab}$ & 68,19 \\
Média & 38,68 & 45,12 & 50,27 & \\
\hline
\end{tabular}

Mesmas letras maiúsculas entre gramaturas e minúsculas entre adesivos não diferem entre si pelo teste Tukey a 5\% de significância. 
As juntas coladas com adesivos à base de mamona e fenol-formaldeído apresentaram os maiores percentuais de falha na madeira seca. Por outro lado, o adesivo de silicato apresentou o menor percentual, comprovando a baixa resistência do adesivo na madeira.

Observa-se que o adesivo à base de mamona apresentou maior valor médio de falha na madeira quando utilizado na menor gramatura, igual a $150 \mathrm{~g} / \mathrm{m}^{2}$, ou seja, a menor quantidade de adesivo aplicada nas juntas coladas foi suficiente para promover maior resistência do adesivo na linha de cola. Petrauski et al. (2010) utilizaram o adesivo a base de mamona na gramatura $160 \mathrm{~g} / \mathrm{m}^{2}$ e observaram percentuais de falha na madeira inferiores a $50 \%$.

Para avaliar a qualidade da colagem da madeira existem algumas normas, como as normas norte-americanas D905-98 e D2339-98, que versam sobre os procedimentos para determinação da capacidade de adesão da madeira: ambas exigem que entre os resultados dos testes sejam reportados a resistência das juntas coladas e o percentual de falha na madeira, bem como a variabilidade desses resultados (ASTM, 2000).

Ainda segundo as normas ASTM D2559-99 e D5771-99, que fornecem, respectivamente, as especificações exigidas para o uso estrutural e não estrutural de componentes de madeira colada, as amostras testadas devem apresentar pelo menos 75\% e 60\% de falha na madeira, respectivamente. Valores altos para o porcentual de falha na madeira são indicativos de boa qualidade na adesão, pois demonstram que a coesão do adesivo e a resistência da interface adesivo-madeira são mais altas que a resistência da própria madeira (ASTM, 2000).
Para o adesivo de fenol-formaldeído, apesar de não ser significativo, verifica-se aumento no percentual de falha na madeira com o aumento da gramatura (Tabela 4).

Vital et al. (2006), estudando a qualidade de juntas coladas com lâminas de madeira oriundas de três regiões do tronco de Eucalyptus grandis, Eucalyptus saligna e Pinus elliottii, obtiveram o menor percentual de falha nas juntas coladas com adesivo a base de resorcinol. Segundo os autores, tal fato pode estar associado ao tipo de filme formado pelo adesivo, pois os adesivos de acetato de polivinila (PVA) formam um filme flexível e, portanto, mais susceptível a maior deformação, e o adesivo resorcinólico forma um filme rígido, menos resistente às tensões aplicadas. Entretanto, neste trabalho, as porcentagens de falha na madeira, condição seca, para o adesivo resorcinol foram maiores do que aquelas observadas para o adesivo de PVA. Fato esse devido, provavelmente, a alta viscosidade apresentada pelo adesivo PVA, que dificultou a fluidez, transferência, penetração e umectação na madeira.

Na Tabela 5 são apresentados os valores percentuais de falha na madeira (\%), condição úmida, das juntas coladas, em função do tipo de adesivo e gramatura. Observou-se que a percentagem de falha na madeira foi afetada significativamente somente para o tipo de adesivo utilizado. A gramatura e interação entre adesivo e gramatura não influenciaram nos percentuais de falha na madeira.

Observou-se, de modo geral, que um aumento da gramatura não contribuiu para aumentar a resistência do adesivo na madeira, exceto para os adesivos de PVA e melamina-formaldeído. Provavelmente durante a prensagem da madeira, a pressão aplicada de $12 \mathrm{kgf} / \mathrm{cm}^{2}$ pode não ter sido homogênea em todos os pontos

Tabela 4. Valores médios para falha na junta colada de madeira (\%), seca, em função da gramatura e tipo de adesivo. Table 4. Mean values for failure glued joint wood (\%), dry, depending on the weight and type of adhesive.

\begin{tabular}{lcccc}
\multirow{2}{*}{ ADESIVO } & \multicolumn{4}{c}{ GRAMATURA $\mathbf{( g / \mathbf { m } ^ { 2 } )}$} \\
\cline { 2 - 5 } & $\mathbf{1 5 0}$ & $\mathbf{2 0 0}$ & $\mathbf{2 5 0}$ & Média \\
FENOL & 62,98 & 62,71 & 65,84 & $63,85 \mathrm{ab}$ \\
SILICATO & 4,82 & 0,00 & 1,92 & $2,24 \mathrm{~d}$ \\
\hline PVA & 19,74 & 24,89 & 17,40 & $20,68 \mathrm{~cd}$ \\
MELAMINA & 42,43 & 55,70 & 19,08 & $39,07 \mathrm{abc}$ \\
MAMONA & 81,61 & 40,14 & 71,10 & $64,28 \mathrm{a}$ \\
RESORCINOL & 28,07 & 46,81 & 29,75 & $34,88 \mathrm{bc}$ \\
\hline Média & $39,94 \mathrm{~A}$ & $38,38 \mathrm{~A}$ & $34,18 \mathrm{~A}$ & \\
\hline
\end{tabular}

Mesmas letras maiúsculas entre gramaturas e minúsculas entre adesivos não diferem entre si pelo teste Tukey a 5\% de significância. 
Tabela 5. Valores médios para falha na junta colada de madeira (\%), úmida, em função da gramatura e tipo de adesivo. Table 5. Mean values for failure glued joint wood (\%), moist, depending on weight and type of adhesive.

\begin{tabular}{lcccc}
\multirow{2}{*}{ ADESIVO } & \multicolumn{4}{c}{ GRAMATURA $\mathbf{( g / \mathbf { m } ^ { 2 } )}$} \\
\cline { 2 - 5 } FENOL & $\mathbf{1 5 0}$ & $\mathbf{2 0 0}$ & $\mathbf{2 5 0}$ & Média \\
\hline SILICATO & 68,89 & 56,33 & 51,66 & $58,96 \mathrm{a}$ \\
PVA & 0,00 & 0,00 & 0,00 & $0,00 \mathrm{c}$ \\
MELAMINA & 0,78 & 2,50 & 4,94 & $2,74 \mathrm{c}$ \\
MAMONA & 23,67 & 32,00 & 64,67 & $40,11 \mathrm{ab}$ \\
RESORCINOL & 7,56 & 9,89 & 6,11 & $7,85 \mathrm{bc}$ \\
Média & 41,22 & 53,67 & 21,89 & $38,93 \mathrm{ab}$ \\
\hline
\end{tabular}

Mesmas letras maiúsculas entre gramaturas e minúsculas entre adesivos não diferem entre si pelo teste Tukey a 5\% de significância.

das juntas coladas, podendo ter gerado uma linha de cola não ancorada, ou seja, o adesivo apresentou suficiente mobilidade para fluir, transferir e penetrar na madeira, mas não o suficiente para ocorrer a umectação, prejudicando a adesão, diminuindo a resistência da linha de cola quando submetida a tensão externa. $\mathrm{O}$ adesivo de PVA apresenta baixa resistência à umidade, sendo restrito a uso interior, entretanto o adesivo de melamina-formaldeído tem como vantagem maior resistência a umidade, o que justifica o maior percentual de falha na madeira em relação ao PVA.

As resinas poliuretanas têm como característica alta resistência à umidade, no entanto os valores médios de falha na madeira observados neste trabalho foram menores que $10 \%$. Provavelmente, pode ter contribuído para esse resultado o fato de esse adesivo apresentar alta viscosidade, portanto baixa fluidez, o que acarreta em dificuldade para espalhar o adesivo sobre a madeira e compromete a ligação adesiva. Outro fato que também pode ter contribuído para esse resultado é a rápida reação entre o poliol e o endurecedor (isocianato), que pode ter ocasionado uma pré-cura do adesivo antes de a pressão ser aplicada. Os adesivos poliuretanos bicomponentes possuem cura rápida na temperatura ambiente, podendo apresentar cura incompleta se os dois componentes não forem misturados adequadamente (Vilar, 2002; Frihart, 2005).

\section{CONCLUSÕES}

O tipo de adesivo utilizado na colagem da madeira influenciou na resistência ao cisalhamento na linha de cola tanto na condição seca como na condição úmida.
A variação da gramatura não teve efeito sobre a resistência ao cisalhamento e falha na madeira.

Houve efeito da interação entre o tipo de adesivo e a gramatura para a resistência ao cisalhamento na condição úmida.

Os adesivos de mamona e resorcinol apresentaram maior resistência ao cisalhamento na linha de cola na condição seca.

Os adesivos de mamona e fenol-formaldeído apresentaram maior percentual de falha na madeira na condição seca.

Os adesivos de fenol-formaldeído e melamina-formaldeído apresentaram maior percentual de falha na madeira na condição úmida.

$\mathrm{O}$ adesivo de silicato de sódio apresentou menor valor de resistência ao cisalhamento e falha na madeira nas condições seca e úmida.

Os adesivos de silicato de sódio e PVA não devem ser utilizados em ambientes úmidos.

\section{AGRADECIMENTOS}

A Deus; À CAPES; À Universidade Federal de Viçosa; A todas as pessoas que direta ou indiretamente contribuíram para esta pesquisa.

\section{STATUS DA SUBMISSÃO}

Recebido: 07 fev., 2014

Aceito: 26 jun., 2016 


\section{AUTOR(ES) PARA CORRESPONDÊNCIA}

\section{Juliana Jerásio Bianche}

Departamento de Engenharia Florestal, Universidade Federal de Viçosa - UFV, Avenida Purdue, s/n, Campus Universitário, Edif. Reinaldo de Jesus Araújo, CEP 36570-900, Viçosa, MG, Brasil e-mail: juliana.bianche@ifmg.edu.br

\section{REFERENCIAS}

Almeida VC. Efeito da adição de carga e extensor nas propriedades do adesivo uréia-formladeído e dos compensados de pinus e paricá [dissertação]. Viçosa: Universidade Federal de Viçosa; 2009.

American Society for Testing and Materials - ASTM. ASTM D-2339: Annual Book of ASTM Standards. Philadelphia: ASTM; 1993. v. 4.10.

American Society for Testing and Materials - ASTM. Annual book of ASTM standards. West Coshohocken: ASTM; 2000. 600 p. v. 15.06 - Adhesives. Section 20.

Associação Brasileira de Normas Técnicas - ABNT. NBR-ISO 12466-1:2006: Madeira compensada- qualidade de colagem. Parte 1: Métodos de ensaio. Rio de Janeiro: ABNT; 2006.

Azevedo ECO. Efeito da radiação nas propriedades mecânicas do adesivo de poliuretana derivado do óleo de mamona [tese]. Curitiba: Universidade Federal do Paraná; 2009.

Carneiro ACO, Vital BR, Pimenta AS, Della Lucia RM. Propriedades de chapas de flocos fabricadas com adesivo de ureia-formaldeído e de taninos de casca de Eucalyptus grandis W. Hill exMaiden ou de Eucalyptus pellita F. Muell. Revista Árvore 28(5), 715-724, 2004. http://dx.doi. org/10.1590/S0100-67622004000500011.

Carneiro ACO. Efeito da hidrólise ácida e sulfitação de taninos de Eucalyptus grandis $w$. hillexmaiden e Anadenanthera peregrina speg., nas propriedades dos adesivos [tese]. Viçosa: Universidade Federal de Viçosa; 2006.

Dias AA, Azambuja M, Oliveira SF Jr. Análise estatística comparativa entre adesivos poliuretanos frente ao resorcinol-formaldeído aplicados em emenda dentada estrutural para espécie Eucalyptus grandis. In: Anais do XVII Congresso Brasileiro de Engenharia e Ciência dos Materiais - CBECIMat; 2006; Foz do Iguaçu. São Paulo: IPEN; 2006.

Fiorelli J. Utilização de fibras de carbono e de fibras de vidro para reforço de vigas de madeira [dissertação]. São Carlos: Instituto de Química e Física de São Carlos, Universidade de São Paulo; 2002.

Forest Products Laboratory. Wood handbook: wood as an engineering material. Madison: U.S. Department of Agriculture; 1999. 463 p.
Frihart CR. Wood adhesion and adhesives: handbook of wood chemistry and wood composites. Boca Raton: CRC Prews; 2005.

Iwakiri S, editor. Painéis de madeira reconstituída. Curitiba: FUPEF; 2005. 247 p.

Jesus JMH. Estudo do adesivo poliuretano à base de mamona em madeira laminada colada (MLC) [tese]. São Carlos: Escola de Engenharia de São Carlos, Universidade de São Paulo; 2000

Lima CKP, Mori FA, Mendes LM, Trugilho PF, Mori CLS. Colagem da madeira de clones de Eucalyptus com três adesivos comerciais. Revista Scientia Forestalis 2008; 36(77): 73-77.

Marcati CR, Della Lucia RM.Comportamento do angicovermelho (Piptadenia peregrinabenth.) à adesão com PVA (acetato de polivinila) e resorcinol formaldeído. Revista Cerne 1996; 2(1): 7.

Mendoza ZMSH. Efeito da inclusão laminar nas propriedades de painéis aglomerados fabricados com resíduos da indústria laminadora [tese]. Viçosa: Universidade Federal de Viçosa; 2010.

Petrauski SMFC, Carneiro ACO, Petrauski MC, Petrauski A. Avaliação de juntas coladas com adesivos poliuretanos. In: Anais do XII Encontro Brasileiro em Madeiras e em Estruturas de Madeira - Ebramem; 2010; Lavras. Lavras: Universidade Federal de Lavras; 2010.

Pizzi A, Mittal KL. Handbook of adhesive technology. New York: Marcell Dekker; 1994. 680 p.

Pizzi A. Advanced wood adhesives technology. New York: Marcell Dekker; 1994. 289 p.

Plaster OB, Oliveira JTS, Abrahão CP, Braz RL. Comportamento de juntas coladas da madeira serrada de Eucalyptus sp. Revista Cerne 2008; 14(3): 251-258.

Teles RF, Menezzi CHSD, Souza F, GB Jr, Souza MR. Efeito da gramatura sobre a qualidade de juntas coladas para a espécie Sextonia rubra. In: Anais do XII Encontro Brasileiro em Madeiras e em Estruturas de Madeira - Ebramem; 2010; Lavras. Lavras: Universidade Federal de Lavras; 2010.

Vilar WD. Química e tecnologia dos poliuretanos [online]. 3. ed. Rio de Janeiro: Vilar Consultoria; 2002. [citado em 2010 Set. 25]. Disponível em: http: www.poliuretanos.com.br Vital BR, Maciel AS, Della Lucia RM. Qualidade de juntas coladas com lâminas de madeira oriundas de três regiões do tronco de Eucalyptus grandis, Eucalyptus saligna e Pinus elliotti. Revista Árvore 2006; 30(004): 637-644. http://dx.doi.org/10.1590/S0100-67622006000400017.

Vital BR. Métodos de determinação da densidade da madeira. Viçosa: UFV; 1984. Boletim técnico, n. 1.

Zangiácomo AL. Emprego de espécies tropicais alternativas na produção de elementos estruturais de madeira laminada colada [dissertação]. São Carlos: Escola de Engenharia de São Carlos, Universidade de São Paulo; 2003. 